\section{Cross-national research to help countries prepare for an aging population 1}

Key words: aging, health economics, public health policy, public health research.

\footnotetext{
1 Based on: National Research Council. Preparing for an aging world: the case for cross-national research. Washington, D.C.: National Academy Press; 2001.
}

In both developed and developing countries around the world the population is aging at an accelerated pace. This shift in age structure raises a number of concerns for policymakers, including: Are people living longer, healthier lives, or do their added years come with disabilities and poor health? How can health systems best adapt to the needs of older populations, with their higher prevalence of chronic disease? How do changes in family structure affect the demand for public transfers of money, time, and space? How do changes in the ratio of workers to retirees affect the ability of societies to fund old-age security systems? Will shifting age distributions result in increased or decreased national saving and investment?

Countries will vary in their policy responses to these and other, related issues. These differing responses will produce a number of "natural experiments" and give countries the chance to learn from each other. To make use of this opportunity, the National Institute on Aging of the United States of America asked the National Academies of the United States, through its National Research Council, to convene a panel that would provide recommendations for an international research agenda on these issues as well as suggestions for the types of data needed to implement that research agenda.

\section{THE RATIONALE FOR CROSS-NATIONAL RESEARCH}

Each country's approach to social policy is a function of unique historical and cultural developments. However, countries can benefit in a variety of ways from cross-national research. Such research, for example, can allow countries to compare performance. Why, for example, might poverty rates among the elderly differ substantially among neighboring countries? Why do estimates of healthy life expectancy vary widely among countries with similar levels of gross national product (GNP) per capita and well-developed health care systems?

Cross-national comparisons can also be powerful motivators for change. The highlighting of differences among nations raises questions about whether national trends are unique and culturespecific or are instead more universal and more fundamental to the human aging process. Compar- 
isons encourage researchers and policymakers to reevaluate existing data, help them identify best practices for similar programs, and facilitate consideration of appropriate interventions.

Comparative research also enhances understanding of variations in the underlying dynamics of population aging and the effectiveness of similar policies and programs in different national settings. For example, some cross-national research suggests that the trend toward early retirement in industrialized nations may have been induced in part by public pension systems themselves. That is, the benefit structure intended to provide earnings replacement at older ages also offers strong incentives for early retirement, thereby intensifying the financial pressures on the system itself. This finding implies a causal relationship between policies designed to ensure against substantial loss of income at older ages and retirement behavior. This result also highlights the importance of research on system design features that can provide such protection in ways that have the least impact on behavior.

The cost of doing high-quality research also argues for comparative study. Many of the studies needed to capture the complexities of the aging process are relatively expensive, and they may be too costly for many nations to do on their own. An obvious strategy is for countries to coordinate their research on population aging in order to crossfertilize the scientific knowledge base and to obtain maximum leverage from relatively modest public investments.

\section{KEY DOMAINS FOR CROSS-NATIONAL RESEARCH}

The National Academies panel focused on five interrelated research domains in which new international data are needed in order to inform policy-making in the coming decades: work and retirement, savings and wealth, family structure and intergenerational transfers, health and disability, and well-being. The relative importance of these five is likely to differ from society to society and may change over time within a given country.

\section{Work, retirement, and pensions}

The declining labor force participation of older persons in many developed countries is one of the most dramatic economic trends of recent decades. The increasing financial pressure faced by public pension systems around the world is often attributed to demographic trends that have led to aging populations. But decreasing labor force par- ticipation rates for a given age structure also contribute to financial imbalances within pension programs, further increasing the number of retired persons relative to those in the workforce and worsening the financial problems that countries face.

In many nations, disability and unemployment insurance programs effectively provide for early retirement before the explicit early retirement age. Such programs must be considered in conjunction with the public pension program itself when social security reform is contemplated. A person who is eligible for disability benefits, for example, typically experiences much stronger early retirement incentives than one not eligible for these benefits. Eligibility usually depends on program provisions and individual circumstances that are often difficult to determine solely from administrative or survey data.

While the public pension system is the principal source of retirement benefits in many countries, in other countries it is only one of several important sources. In the Netherlands, the United Kingdom, the United States, and elsewhere, employerprovided pension plans are a key source of benefits. The incentive effects of these private plans can be quite similar to those of public pension programs. For many developing countries that are just designing pension programs with private as well as public components, there are opportunities to learn from the trials and errors of wealthier nations.

\section{Private wealth and income security}

Income security during retirement, along with an increase in the length of the post-retirement period, is one of the primary social achievements of the twentieth century in most industrialized nations. At the same time, this accomplishment has introduced some fundamental public policy challenges associated with population aging. The two most basic challenges are: 1) that individuals have sufficient income security during their retirement years so that retirement does not lead to a substantial decline in living standards and 2) that individuals are protected against the increasing risk of experiencing periods of poor health. From a policy viewpoint, these challenges involve critical interrelationships, including between health and economic status and between public policy and individual behavior.

Although economists have gained a better understanding of individual savings and investment decisions and how these decisions interact with policy, numerous questions remain. Such questions can be answered only if adequate data are available. In 
very few countries is there substantial information about health in combination with wealth. Given the important interaction among health status, work status, and the amount of wealth accumulated over the life course, this is a serious omission. Nevertheless, the quality of the existing wealth surveys is good in some developed countries, and careful cross-national comparisons using the data from these surveys could produce useful information. In many other countries, however, such data do not exist and will have to be developed.

\section{Transfer systems}

The well-being of older persons depends to a large extent on the content and volume of an intricate set of transfer systems in which they are engaged over their lifetimes. In industrialized countries the most salient of these systems are associated with individual savings behavior (representing transfers over individual life cycles), exchanges with family members, and intergenerational transfers from current workers to nonworkers through many types of social security and pension programs. Individuals usually participate in a variety of transfer systems concurrently, with the mix varying across individuals and societies, as well as over the life course. The older generation in many countries is particularly likely to be involved in a complex series of exchanges involving public programs, employers, and family members, with significant shifts in salience and magnitude often occurring with age.

Although considerable progress has been made in understanding the volume, content, and implications of each major transfer system, many gaps remain. Particularly deserving of attention are interrelationships across systems and how changes in one system (for example, public pensions) affect another (for example, the level and direction of family support).

Many of the key transfer systems can be understood and measured at both the individual and family levels, as well as at the societal or macro level. This complexity poses further challenges to the tracing of interrelationships across systems. A microbehavioral approach is the major perspective for studying family exchanges, while macroeconomic analysis is the dominant strategy for studying public and employer transfer arrangements. The mix of transfer programs and their relative importance vary considerably between the moredeveloped and the less-developed economies, and within both of these groups as well. This variation in approaches, incentives, and reactions to new programs and societal changes provides a continuum of experience whose study can greatly illuminate the dynamics of each system and the interrelationships across systems.

\section{The health of aging populations}

Health plays an important role in the social outcomes associated with the other substantive research areas discussed in this report: retirement, wealth accumulation, transfer systems, and wellbeing. It is critical, therefore, that appropriate health data be collected to use in models intended to explain differences in these substantive outcomes within and across countries. At the same time, health is a critical policy variable in its own right. Although population aging may or may not result in increasing proportions of elderly persons in poor health, the numbers experiencing that condition are almost certain to increase. Thus, as the populations of all industrialized countries and most developing countries age, the social and economic demands on individuals, families, communities, and nations will grow, with a substantial impact on formal and informal medical and social care systems and on the financing of medical services in general.

In conjunction with growing numbers of older persons, most nations face secular changes in health status, as reflected in rates and outcomes of various conditions and disabilities. For example, rates of heart attack and stroke are decreasing in many countries, while such trends may not be obvious for cancers. Some nations are experiencing rising AIDS rates among older persons. Research increasingly suggests declines in rates of severe physical disability among older persons in developed nations, although the cross-national comparability of such findings remains problematic. Trends in cognitive impairment and dementia have enormous policy implications, but our time-series knowledge base is lacking. Whether changes in disease and disability rates alter the rates of long-term institutionalization within and among nations is also unclear.

While all countries must address the changing health needs of their older citizens, the nations' approaches are surprisingly diverse in terms of health system organization, administration, and financing. At the same time, national health systems themselves are in transition.

Nevertheless, effective cross-national and cross-cultural research demands suitably comparable data on health status and outcomes, on informal and alternative sources of medical and social services, and on health system administration and financing. These data must come from a variety of sources, including vital statistics and administrative records, research studies, population censuses, 
health outcome evaluations, and geographically defined longitudinal population surveys that assess the trajectories of the health, social, and economic status of families with older persons. Such information frequently is nonexistent, inaccessible, or nonstandardized, making it difficult if not impossible to conduct high-quality, informative cross-national research on health.

\section{Well-being}

The supreme criterion by which the success of a government can be judged is the quality of life its citizens experience from birth to death. Questions of well-being are particularly important during major life transitions, both because such transitions provide a specific frame of reference for the assessment of well-being and because they involve significant changes in activity patterns. Proposals for the continuing assessment of well-being have been put forth for at least a half century. Despite these proposals and a wide range of research efforts by academics, there is no consensus on the conceptual definition, conceptual levels, or measurement of well-being.

Cross-national research on aging should include the development of overall measures of subjective well-being (life satisfaction), as well as further development and assessment of measures of emotional states and moods. Cross-national comparisons should also include the experience of major life events, especially those stressful events that are increasingly likely in old age, such as illness, bereavement, complete or partial retirement, and changes in activity patterns.

\section{CHALLENGES TO DOING CROSS-NATIONAL RESEARCH}

While the theoretical benefits of comparative international research for policy-making are increasingly clear, the conduct of such research poses a number of challenges, according to the National Academies panel. Among the most important of these are developing research questions and designs that can be readily adapted to different social and cultural settings, harmonizing concepts and measures that provide a reasonably acceptable level of cross-national comparison, and coordinating data collection and analysis across countries.

Each of these challenges represents a major undertaking. Recent decades have seen heightened sensitivity to and substantial technical advances in the validation of measures in different cultural settings, yet many problems remain. Data on the same variable or process may differ in myriad small ways. A prime example is the measuring of activity restriction among older adults by using a set of indicators commonly called "activities of daily living" (ADLs). The World Health Organization has recommended the use of a particular ADL instrument. However, a recent analysis of surveys in nine European nations showed that while the use of a set of ADL questions is widespread, there are significant differences among the surveys in both wording and the items included. These differences hinder comparison of the prevalence of ADL restrictions among countries.

In some cases, cross-national measurement problems are easy to correct. In other cases, the theoretical idea is well understood but is hard to implement. One example is the conversion of monetary units to a common value. Simple equations can be used to convert from one currency to another, but this conversion may not reflect the true purchasing power in the two countries. For many variables used in studies of health, psychology, and economics, methods for obtaining common measurements are not well understood, in part because they have received inadequate systematic attention from the scientific community.

Analyzing data without shared protocols can lead to misleading conclusions. Careful planning of the collection and exchange of comparable data would have long-term benefits that could be shared by countries that now have limited capacities to implement major data initiatives on their own.

\section{MAJOR, OVERARCHING RECOMMENDATIONS}

For each of the five research domains, the National Academies panel made suggestions for conducting appropriate studies. In addition, the panel developed six key global recommendations that are essential for carrying out effective crossnational research and for generating data for policy decisions.

\section{Multidisciplinary research designs to produce data on aging populations}

Public policy must be guided by an understanding of the interplay of multiple factors, including relationships between health and retirement decisions, between economic status and health, and between family structure and wellbeing in older age. Initiatives in various countries to integrate several key domains of people's lives into single survey instruments have proven successful. 
These domains have included income and wealth, labor force activity and retirement, health status and utilization of health care facilities, cognition, and intergenerational transfers. These efforts could serve as models and building blocks for research in both developed and developing countries.

Extended interaction among demographers, economists, epidemiologists, social psychologists, sociologists, and statisticians is absolutely key to a variety of essential tasks, including: 1) creating and refining harmonized measures that are conceptually comparable across societies and that can be used to better understand such outcomes as labor force participation, health and disability status, complex family relationships, and economic status and 2) developing databases that can be used to maximize the potential of cross-national and crosstemporal research for identifying the determinants of critical outcome variables.

There also must be a continuing and effective dialogue between the policy community and researchers that results in the design of a program of data collection that can properly inform policymakers. This exchange must be ongoing since many of the key dimensions of population aging can be expected to change as socioeconomic circumstances evolve.

\section{Longitudinal research to clarify the interrelationships among work, health, economic status, and family structure}

There is a pressing need in most countries for longitudinal microdata that include extensive measures of economic status, financial incentives to retire, various aspects of health status, and intergenerational relations and transfers. Such data are needed to better understand patterns of age-related transition along these dimensions, interrelationships among the dimensions, and ultimately the ways in which these domains contribute to overall well-being. With some degree of certainty, it is possible to anticipate the demographic parameters and trends that give rise to broad policy issues. Much less is known about individual responses to policy interventions, for example the labor supply response to a restructuring of public pension plans that raises the early retirement age. Ultimately, policy options are grounded in understanding individual and family behaviors and their responsiveness to changing life circumstances.

From a research standpoint, the variation in response patterns associated with changing circumstances implies the need for panel studies that trace cohorts over time. Studies can be repeated cross sections, single-cohort panel studies, or panel stud- ies that continue to add new cohorts at the bottom end of the age range and are thus continually representative of the study population. If affordable, panel studies that add new cohorts are clearly best, since they not only capture the dynamics of change over time for individuals but also continue to describe the broader population and not just a single cohort. Population aging is likely to require the careful attention of policymakers for at least the next five decades, so neither repeated cross sections nor single-cohort designs are very attractive. Interestingly, panel studies that add new cohorts may be less expensive than repeated cross sections with the same frequency, sample size, and length, simply because the cost of reinterviews is much lower than that of initial interviews.

\section{National and international mechanisms to facilitate the harmonization and standardization of data collected in different countries}

Major scientific and policy gains would be possible if a number of countries could be persuaded to embark on data design and collection activities that would provide a rich set of comparable, harmonized data, with procedures for sampling and quality control synchronized as much as possible. Advantages would come from the confluence of several factors: the differential rates of population aging throughout the world that result from differences in fertility and mortality histories; the concomitant economic and social changes (e.g., in pension reform, marriage and divorce rates, schooling levels, and adoption of innovative medical technology) that are occurring differently throughout the world; and the growing awareness among policymakers that global aging will pose major economic and social challenges for the next half century. Much of the needed harmonization can probably be achieved through extensive exchange of information among scientific groups working on new data collection efforts.

This emphasis on harmonization does not imply that survey protocols need to be identical in all counties. Prior attempts to impose standardized data collection approaches across countries have produced mixed results. Each country has unique institutional features and policy priorities that shape data collection and research. For example, while all countries are likely to regard estimates of household wealth as an important element of their data collection activity, they are unlikely to measure the same components. On the other hand, disability, disease, and functional health need to be measured in a standardized way to enable accurate cross-national analysis. 
An emphasis on cooperative cross-national research to facilitate the evaluation of institutional and programmatic features of policy related to aging

Cross-national studies conducted within a framework of comparable measurement can be a substantially more useful tool for the analysis of policy impact than studies of single countries. A cross-national perspective provides a broader and richer set of institutional arrangements within which to understand policy initiatives, and offers opportunities to relate variations in institutional arrangements to the distribution of attributes that determine program eligibility, benefit levels, and, ultimately, individual and household behaviors.

Sophisticated comparative analyses can exploit differences and changes in policy rules across countries by isolating their impacts from those of other macroeconomic and social changes. For example, research on 11 developed countries revealed three important features that could not easily have been discerned from single-country studies. First, the data showed a strong correspondence between early and normal retirement ages and the probability of departure from the labor force. Second, public pension provisions in many countries were found to place a heavy tax burden on work past the age of early retirement eligibility, and therefore to provide a strong incentive for early withdrawal from the labor force. Third, this implicit tax-and hence the incentive to leave the labor force-varied substantially among the countries, as did retirement behavior. Therefore, comparisons across the countries made it possible to draw several general conclusions about the relationship between retirement incentives and retirement behavior.

In general, at least three conditions must be met to provide an accurate assessment of policy impacts on behavior. If the policy is considered a "treatment," then: 1) there must be a sizable comparison (untreated) group with observable characteristics similar to those of the treatment group; 2) the comparison group must be unaffected by the policy, that is, there are no spillover effects; and 3) the treatment and comparison groups must be subject to the same socioeconomic trends over time. Cross-national comparisons can help on all three of these counts. Policy interventions typically occur in one country but not elsewhere, meaning that valid comparison groups generally exist across but not within countries. Comparison groups in other countries are unlikely to be affected by a policy intervention in one country, so that spillover effects within countries do not necessarily distort the estimated impact of the intervention. Finally, compari- son groups can be selected on the basis of characteristics that suggest relatively similar life experiences, such as by comparing individuals with high incomes and education levels across countries. And even when within-country variation is informative, cross-country comparisons can add substantially to the variability in the data and thereby improve the precision of forecasts of a policy intervention's impact.

\section{The consolidation of information from multiple sources to generate linked databases}

Integrating different types of information (e.g., survey, census, administrative, and medical) produces a data set whose depth and explanatory power exceed what is possible for any single source. The advantage of linking survey data with administrative records is that the latter are likely to contain extended histories that could not be obtained from a survey, or if obtainable, would be associated with significantly higher measurement error. Under ideal conditions, therefore, administrative records can provide unbiased measures of change over time for a standard set of concepts. The ability to merge data of this sort with data tailored to the analytic issues addressed by surveys clearly has major advantages.

Beyond the scientific advantages, the linking of administrative and other information with survey data reduces respondent burden, a notinsignificant factor given the complexities of survey research instruments and the reluctance that many people have to participating in surveys.

\section{Widespread and unconstrained access to the data obtained using this research approach}

Good data are public goods for both policy and research. Scientific advances and policy insights that may emerge from the development of a data set are greatly enhanced if a broad community of scientific users with different interests, theoretical perspectives, and models have ready access to the information. One example of how data can be made available to the research community at large is the Health and Retirement Survey (HRS) in the United States, begun in the early 1990s. Perhaps the most important reason for the widespread use of the HRS data is that they are made readily available via the Internet to both scientists and policymakers. Using these data, more than 300 scientific papers have been written, including many by researchers from outside the United States. 
In many countries, researchers' access to data is severely limited or unnecessarily costly in terms of time and/or money. Because of this restricted access and the limited role of scientists in the design of surveys, scientific innovation in the collection of data is hampered. Moreover, scientists in these countries often choose to use data from other countries to test their ideas since it is too difficult to use their own national data. All surveys involve legitimate and thorny issues of privacy and confidentiality that must be explicitly addressed and resolved. Nevertheless, there are statistical and legal methods for preserving confidentiality that can be used without unduly limiting scientific access to data.

Entitled Preparing for an Aging World: The Case for Cross-National Research, the complete report based on the work of the National Academies panel can be purchased from the National Academy Press (NAP), 2101 Constitution Avenue, N.W., Lockbox 285, Washington, D.C. 20055, United States of America, telephone (202) 334-3313 or (800) 624-6242. The report can also be purchased from the NAP Web site (http://www.nap.edu), which also offers free page-by-page viewing of the full document.

\section{SINOPSIS}

\section{Investigación internacional para ayudar a los países a prepararse para el envejecimiento de la población}

La población está envejeciendo a paso acelerado en los países desarrollados y en desarrollo de todo el mundo. Este cambio demográfico suscita problemas políticos importantes a los cuales cada país dará respuestas diferentes, lo cual permitirá que aprendan unos de otros. Para aprovechar esta oportunidad, el Instituto Nacional del Envejecimiento de los Estados Unidos de América les pidió a las Academias Nacionales de ese país que, a través de su Consejo Nacional de Investigación, convocara un grupo de expertos que recomendara un programa de investigación internacional sobre el envejecimiento y estableciera qué tipo de datos son necesarios para ponerlo en práctica. Dicho grupo se centró en cinco campos de investigación interrelacionados: trabajo y jubilación; ahorros y riqueza; estructura familiar y transferencias intergeneracionales; salud e incapacidad, y bienestar. Para cada uno de ellos hizo sugerencias sobre cómo llevar a cabo los estudios apropiados. Además elaboró seis recomendaciones globales que son fundamentales para realizar investigaciones internacionales eficaces y generar datos en los que basar las decisiones políticas. 